TP Periodica Polytechnica Civil Engineering

\author{
62(2), pp. 346-352, 2018 \\ https://doi.org/10.3311/PPci.11247 \\ Creative Commons Attribution (i)
}

RESEARCH ARTICLE

\section{Saturation Point of Superplasticizers Determined by Rheological Tests for Self Compacting Concrete}

\author{
Mehena Oualit $^{1 *}$, Amar Irekti ${ }^{1}$, Yannick Melinge ${ }^{2}$
}

Received 11 July 2017; Revised 09 October 2017; Accepted 14 November 2017

\begin{abstract}
The dosage of superplasticizer is first determined in mortar mixtures and it is after adjusted in concrete mix trials. Other self compacting concrete (SCC) mix proportioning methods rely on the definition of the superplasticizer saturation dosage in pastes. These approaches to mix design have advantages over the ones based exclusively on concrete batching because it is less expensive and material demanding to perform tests in mortar and paste than in concrete. This paper presents the results of an experimental research carried out to investigate the use of tests performed in paste to define the optimum dosage of superplasticizer for self-compacting concrete. The materials employed were Portland cement, pozzolana and three types of superplasticizers: poly naphthalene sulfonate (PNS), poly melamine sulfonate (PMS) and a polycarboxylate. The saturation point of each superplasticizer was determined in pastes by rheological tests using a coaxial cylinder rheometer AR2000. Self-compacting concretes were prepared using the superplasticizer contents found. The results obtained led to the conclusion that in SCC mixture proportioning methods, the determination of the superplasticizer content in the paste phase is paramount. Nevertheless, final adjustment of $w / c+f$ ratio was always needed in order to produce SCC.
\end{abstract}

\section{Keywords}

superplasticizers, saturation dosage, rheological tests, self compacting concrete

\section{Introduction}

Superplasticizers, also called as High Range Water Reducing (HRWR) Admixtures, are micro-molecular organic or chemically synthesized agents which, according to their chemical contents, have been divided into the following four groups [1, 2]: Sulphonate melamine formaldehyde, Sulphonate naphthalene formaldehyde, Modified lignosulphonates and Copolymers containing sulphonic and carboxyl groups which may contain polycarboxylates and polyacrylates [3]. These products are often used as a basic component in self-compacting concretes.

Self-compacting concrete (SCC) is characterized by its filling ability and deformability, which is governed by fluidity and cohesion of the mixture. To these properties should also be added requirements for passing ability and resistance to segregation, which are mostly related to the volume, dimension and distribution of the aggregate particles. These properties can be evaluated in SCC with specific tests, such as Slump flow, V-Funnel and L-Box [4, 5, 6] and sieve stability [7]. SCC can also be characterized by its rheological properties, which are a low yield stress $\left(\tau_{0}\right)$, to guarantee the increase of the fluidity, and a moderate viscosity $(\eta)$, to promote the necessary mixture stability. The yield stress relates with the distance between the particles in the paste matrix and governs the mix deformability, while viscosity is governed by the contact between the particles and it can be used to indicate the resistance to the segregation. Self compacting concrete SCC has been satisfactory described by the Bingham model (Eq. (1)) [9].

$$
\tau=\tau_{0}+\eta \cdot V
$$

Where

$$
\begin{aligned}
& \tau=\text { shear stress } \\
& \tau_{0}=\text { yield stress } \\
& \eta=\text { plastic viscosity } \\
& V=\text { shear rate }
\end{aligned}
$$

One of the critical parameters to be determined during SCC mixture proportioning is the superplasticizer content. The amount of superplasticizer affects the cost and the fresh and early-age properties of the SCC. Excess of superplasticizer can 
cause mixture instability and setting delay; in small amounts, the superplasticizer does not promote the necessary fluidity and problems with fluidity maintenance are verified. Due to its economical and technological importance for the SCC, the definition of an optimum superplasticizer dosage is of extreme importance. Many technologists propose that superplasticizer dosage in concrete should relate well with the saturation dosage determined in studies carried out in cement paste, through the use of viscometers [8], Marsh-cone or mini-slump testing. Others indicate that a satisfactory definition of the superplasticizer content to be used in SCC can derive from studies performed in mortar [9].

This paper investigates the use of tests performed in pastes to define the optimum dosage of superplasticizer for self-compacting concrete. The saturation point interval of superplasticizers was determined in pastes by rheological tests using a coaxial cylinder rheometer AR2000.

\section{Materials and methods}

The materials used in this work come from the north region of Algeria:

\subsection{Cement}

The cement used is the Portland cement without mineral additives CEM I 42.5 with Blaine fineness of $3500 \mathrm{~cm}^{2} / \mathrm{g}$ and specific mass of $3.14 \mathrm{~g} / \mathrm{cm}^{3}$. Its chemical and mineralogical composition is given in Table 1 .

Table 1 Chemical and mineralogical composition of cement

\begin{tabular}{lccc}
\hline Element & $(\%)$ & Mineral & $(\%)$ \\
\hline $\mathrm{CaO}$ & 66.52 & & \\
$\mathrm{SiO}_{2}$ & 23.28 & $\mathrm{C}_{2} \mathrm{~S}$ & 22.9 \\
$\mathrm{Al}_{2} \mathrm{O}_{3}$ & 4.89 & & \\
$\mathrm{Fe}_{2} \mathrm{O}_{3}$ & 1.98 & & \\
$\mathrm{SO}_{3}$ & 0.34 & $\mathrm{C}_{3} \mathrm{~S}$ & 58.12 \\
$\mathrm{Na}_{2} \mathrm{O}$ & & \\
$\mathrm{K}_{2} \mathrm{O}$ & 0.03 & & \\
$\mathrm{MgO}_{\mathrm{CaO}}$ & 0.55 & $\mathrm{C}_{3} \mathrm{~A}$ & 9.6 \\
fire loss & 1.66 & & \\
Insoluble & 0.71 & & 6.02 \\
\hline
\end{tabular}

\subsection{Fine material: Pozzolana}

As fines, a finely ground Pozzolana is used, with a Blaine fineness of $7300 \mathrm{~cm}^{2} / \mathrm{g}$ and pozzolanic activity of $109.65 \mathrm{mg} / \mathrm{g}$. its chemical composition is reported in Table 2.
Table 2 Chemical composition of pozzolana.

\begin{tabular}{lc}
\hline Element & $(\%)$ \\
\hline $\mathrm{CaO}$ & 11.05 \\
$\mathrm{SiO} 2$ & 44.72 \\
$\mathrm{~A} 12 \mathrm{O} 3$ & 16.42 \\
$\mathrm{Fe} 2 \mathrm{O} 3$ & 8.94 \\
$\mathrm{SO} 3$ & 0.07 \\
$\mathrm{Na} 2 \mathrm{O}$ & 3.07 \\
$\mathrm{~K} 2 \mathrm{O}$ & 1.35 \\
$\mathrm{MgO}$ & 4.37 \\
fire loss & 7.24 \\
$\mathrm{Cl}-$ & 0.02 \\
\hline
\end{tabular}

\subsection{Superplasticizers}

Three superplasticizers were used in this experimental study, all from the company GRANITEX.

MEDAFLOW 30: Third-generation water-reducing superplasticizer. It is designed based on ether polycarboxylates. In addition to its main function of superplasticizer, it makes possible to decrease the water content of concrete in a remarkable way. MEDAFLOW 30 does not exhibit a retarding effect. Its physical and chemical characteristics are as follows:

$\begin{array}{ll}\text { - Form } & \text { Liquid } \\ \text { - Color } & \text { Yellowish } \\ \text { - } \mathrm{pH} & 6-6.5 \\ \text { - Density } & 1,07 \pm 0.01 \\ \text { - Chlorine content } & <1 \mathrm{~g} / \mathrm{L}\end{array}$

MEDAFLUID SFA: Superplasticizer - Hardening accelerator. It is an adjuvant based on poly melamine sulfonate PMS. Its physical and chemical characteristics are as follows:
- Form
Liquid
- Color
Translucent
- $\mathrm{pH}$
$7-8$
- Density
$1,20 \pm 0,01$
- Chlorine content
$<\lg / \mathrm{L}$

MEDAPLAST SP 40: Superplasticizer - High water reducer. It is an adjuvant based on poly naphtalene sulfonate PNS. Its physical and chemical characteristics are:
- Form
Liquid
- Color
Brown
- $\mathrm{PH}$
8.2
- Density
$1,20 \pm 001$
- Chlorine content
$<\lg / \mathrm{L}$

\section{Rheological study}

The aim of the rheological study is to highlight the influence of each type of superplasticizer on the rheological behavior of the paste (cement + pozzolana + water) as a function of the percentage of the incorporated superplasticizer and to deduce the saturation dosage of each superplasticizer. 


\subsection{Pastes}

Pastes were prepared according to the same proportions used in self-compacting concretes (Japanese method) [10]. The type and the superplasticizer dosage were varied by $0.25 \%$ with respect to the mass of cement.

The ponderal composition of the paste used in the laboratory is as follows:

- $70 \%$ of cement: $300 \mathrm{~g}$

- 30\% of pozzolana: $129 \mathrm{~g}$

- Water/cement ratio $(\mathrm{w} / \mathrm{c}+\mathrm{f})=0.35$

- Different dosages (\%) of superplasticizer.

The rheological tests were carried out at $20{ }^{\circ} \mathrm{C}$, using an AR2000 rheometer (Fig. 1) equipped with a Rotor valve. The flow curves were analyzed and modeled by Rheology Advantage data Analysis (Version -V4.021).

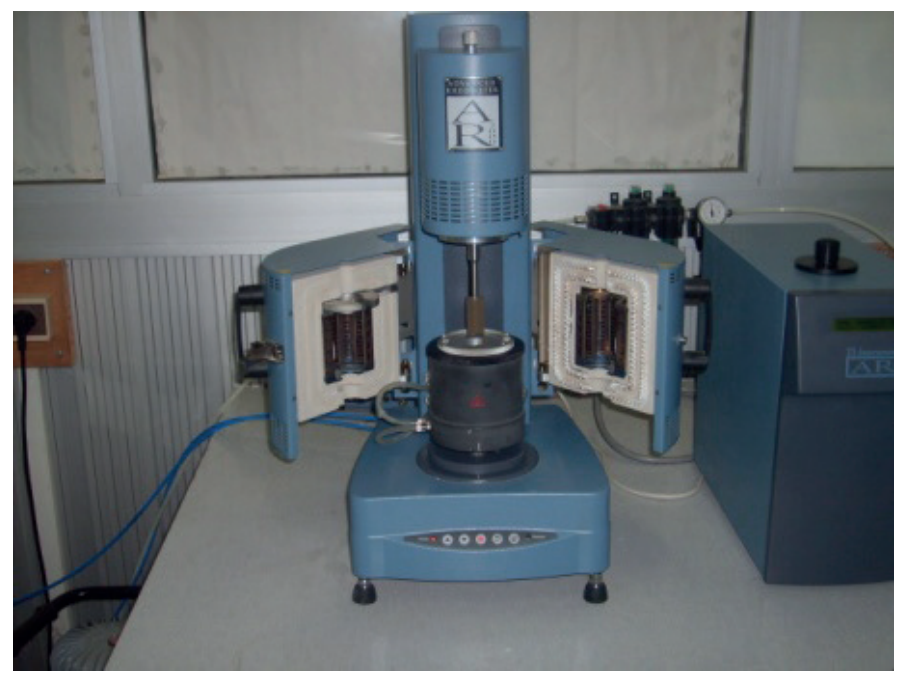

Fig. 1 Rheometer AR2000

\section{Results and discussion}

The different rheological behaviors of the different pastes with each type of superplasticizer are given below:

\subsection{Paste based on polynaphthalene sulfonate PNS}

The rheogram of shear stress as a function of the shear rate of the paste with different dosages of PNS superplasticizer is shown in Fig. 2.

It can be seen in Fig. 2 that the shear stress decreases with the increase of the PNS dosage. Moreover, the shear stress which is $42 \mathrm{~Pa}$ with $0.5 \%$ PNS decreases and reaches about $4 \mathrm{~Pa}$, with a dosage of $1.5 \%$, which means that the suspension becomes more flowable.

Furthermore, with a dosage of $1.75 \%$, the dough flows with minimum effort (minimum yield value). Yield stress $\left(\tau_{0}\right)$ is defined as the force a fluid must be exposed to in order to start flowing. It reflects the resistance of the fluid structure to deformation or breakdown.
Usually, rheograms from rotational viscometer measurements are used as a means to calculate yield stress and viscosity. It can also be obtained by applying rheological mathematical models [11]. There are several rheological mathematical models applied on rheograms in order to transform them to information on fluid rheological behaviour [12].

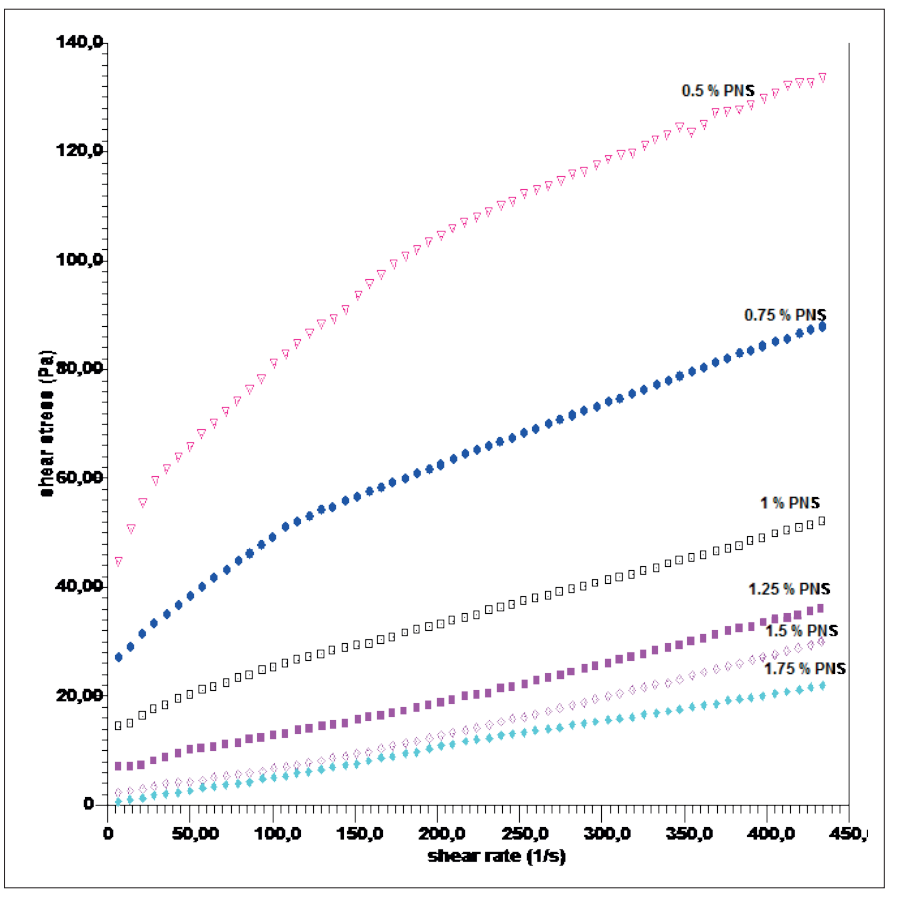

Fig. 2 Evolution of the rheological behavior of cementitious paste at different dosages of PNS.

From the shape of the curves of Fig. 2, it is noted that they are not linear, thus, the rheological behavior of the different pastes is not Newtonian (Non-Newtonian fluids do not show a linear relationship between shear stress and shear rate). Yield stress and viscosity (rheological parameters) were extracted from each of the curves presented in Fig. 2 using Herschel Bulkley (H-B) model. The Herschel Bulkley model is applied on fluids with a non linear behavior and yield stress. It is considered as a precise model since its equation has three adjustable parameters, providing data [13]. The Herschel Bulkley model is expressed in Eq. (2), where $\tau_{0}$ represents the yield stress.

$$
\tau=\tau_{0}+\mathrm{K} \cdot \mathrm{V}^{n}
$$

The consistency index parameter $(\mathrm{K})$ gives an idea of the viscosity of the fluid. However, to be able to compare K-values for different fluids they should have similar flow behavior index $(n)$. When the flow behavior index is close to 1 the fluid's behavior tends to pass from a shear thinning to a shear thickening fluid. When $(n)$ is above 1 , the fluid acts as a shear thickening fluid. 
The Yield stress and the viscosity were plotted versus PNS percentage (these two plots are actually made in the same figure with two different axes (Fig. 3). And, similarly, we plot these two dependences on PMS percentage (Fig. 5), and on polycarboxylate percentage (Fig. 7).

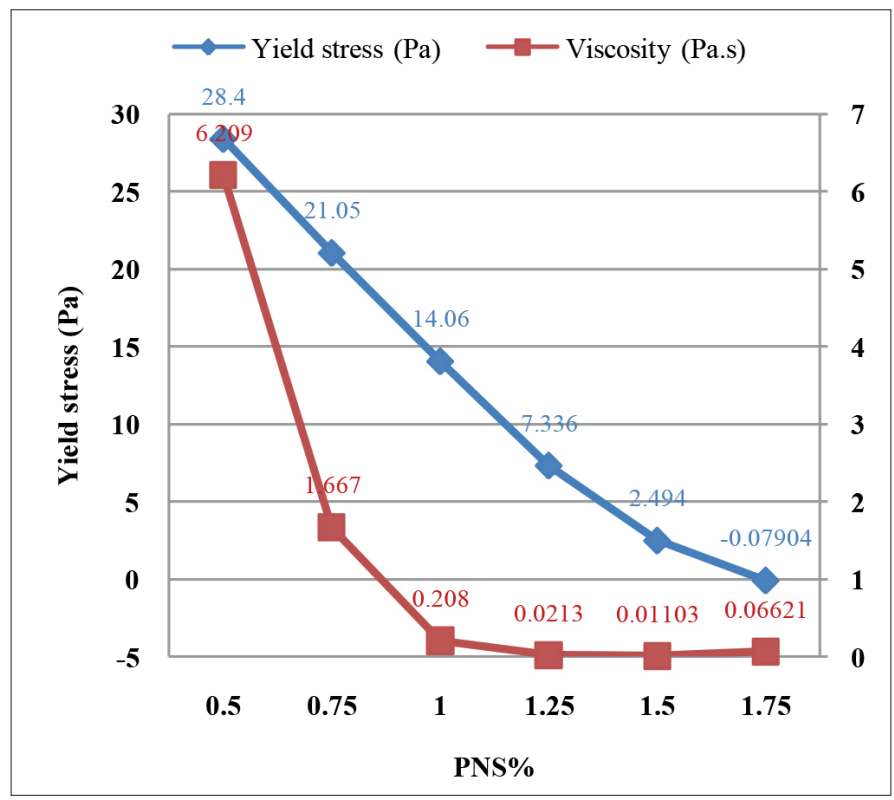

Fig. 3 Evolution of the rheological parameters as a function of PNS \%

From the results of Fig. 3, it may be noted that the yield stress is inversely proportional to the quantity of PNS introduced. In other words, the yield value decreases with the increase of the percentage of PNS, until the last incorporated concentration $1.75 \%$. The viscosity also decreases significantly until a dosage of $1.25 \%$. Beyond this PNS concentration, there is some stabilization with low values ranging from 0.01103 to 0.06621 Pa.s. This can be explained by the dispersing effect of PNS which is adsorbed at the interface of the grains of cement thus creating repulsive forces between the particles, reducing or eliminating squarely the adhesion between the neighboring particles.

\subsection{Paste based on polymelamine sulfonate PMS}

The results of the rheological tests on the paste containing PMS superplasticizer at different percentages are given in Fig. 4. Fig. 5 represents PMS\% dependence of yield stress and of viscosity.

From Fig. 4, it can be seen that the shear stress decreases with the addition of PMS and reaches a minimum value at a concentration of $2.5 \%$ of this superplasticizer.

It is also observed that with a dosage of $0.78 \%$, the shear stress is about $50 \mathrm{~Pa}$ and it drops to $8 \mathrm{~Pa}$ with $2 \%$, which amounts to the dispersion between the particles caused by the effect of the superplasticizer.

It can be concluded that the Newtonian flow is almost reached this time with a concentration of $2.5 \%$ of the PMS dosage.
The rheological behavior of the pastes at different concentrations is not linear; therefore the different suspensions presented in this rheogram do not correspond to Newtonian fluids.

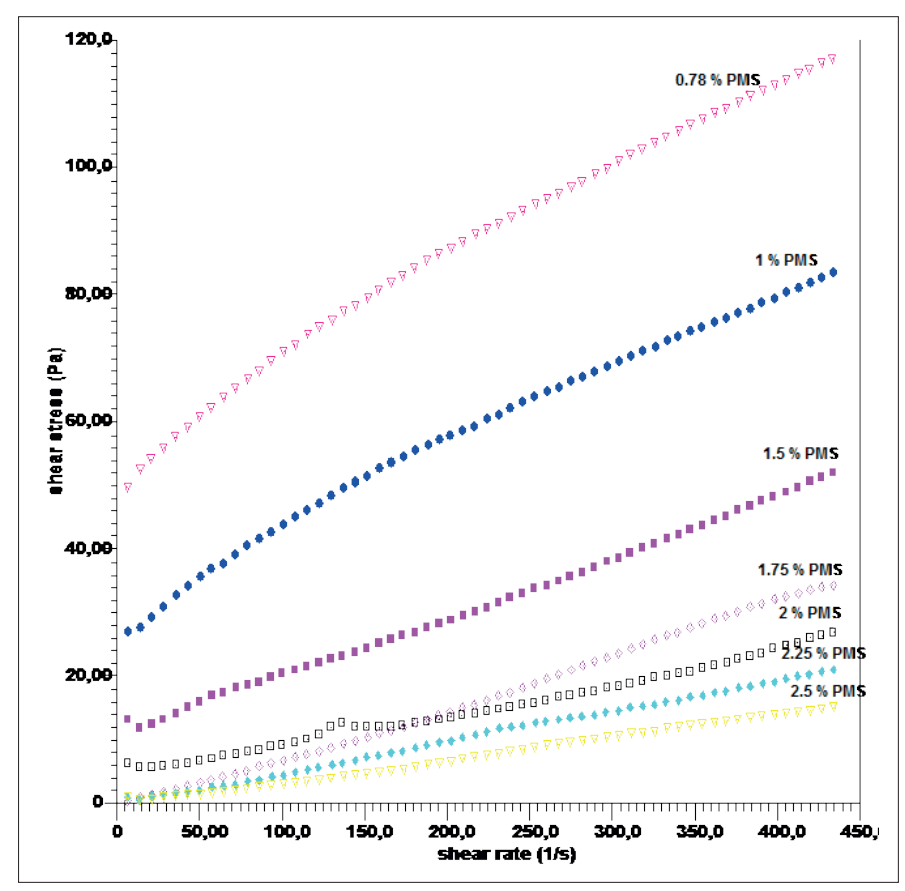

Fig. 4 Evolution of the rheological behavior of cementitious paste at different dosages of PMS

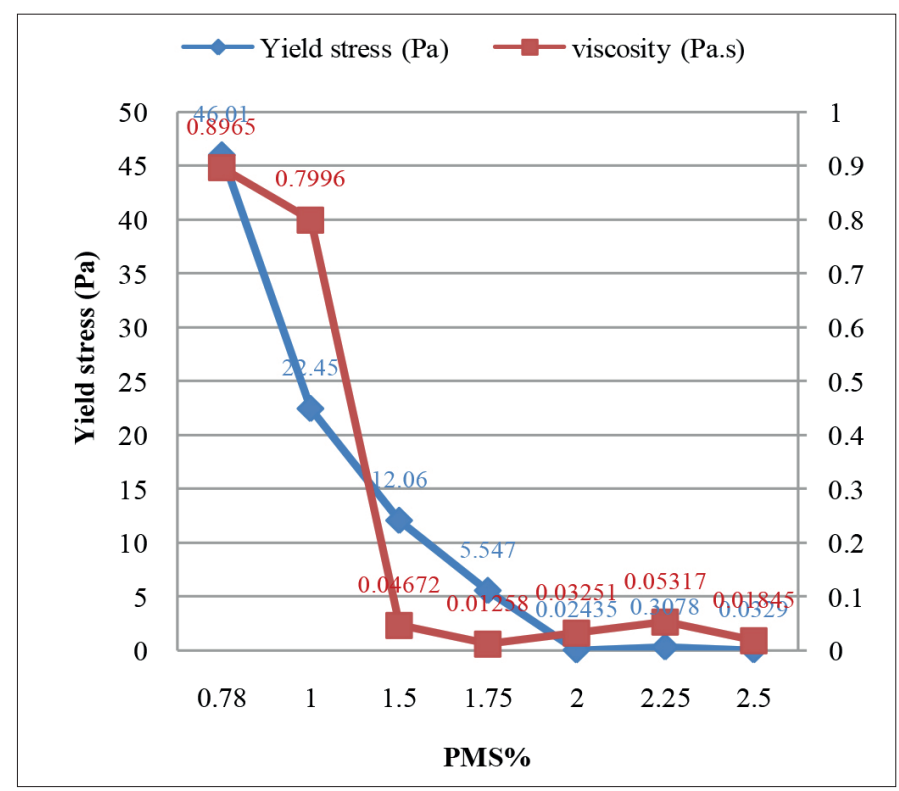

Fig. 5 Evolution of the rheological parameters as a function of PMS \%

Figure 5 shows that yield stress decreases with increasing PMS. From 2\% PMS, the yield stress is relatively stable until reaching the maximum dosage (2.5\% PMS). The highest value is recorded with the minimum adjuvant dosage $(0.78 \%)$ where it reached a value of $46.01 \mathrm{~Pa}$, a relatively high value compared with the previous superplasticizer PNS $(21.05 \mathrm{~Pa}$ at $0.75 \%$ PNS). Regarding the viscosity, the latter also decreases with the increase of the concentration of the superplasticizer until a precise dosage $(1.75 \%$ PMS) before stabilizing with slight fluctuations. 
It can therefore be deduced that the PNS is more effective than the PMS in dispersion. Finally, it can be estimated that these suspensions correspond to Pseudoplastic fluids because since they become thinner when the shear rate increases.

\subsection{Paste based on polycarboxylate}

The same tests were carried out for the paste containing the polycarboxylate. The results are given in Fig. 6. Figure 7 represents polycarboxylate \% dependence of yield stress and of viscosity.

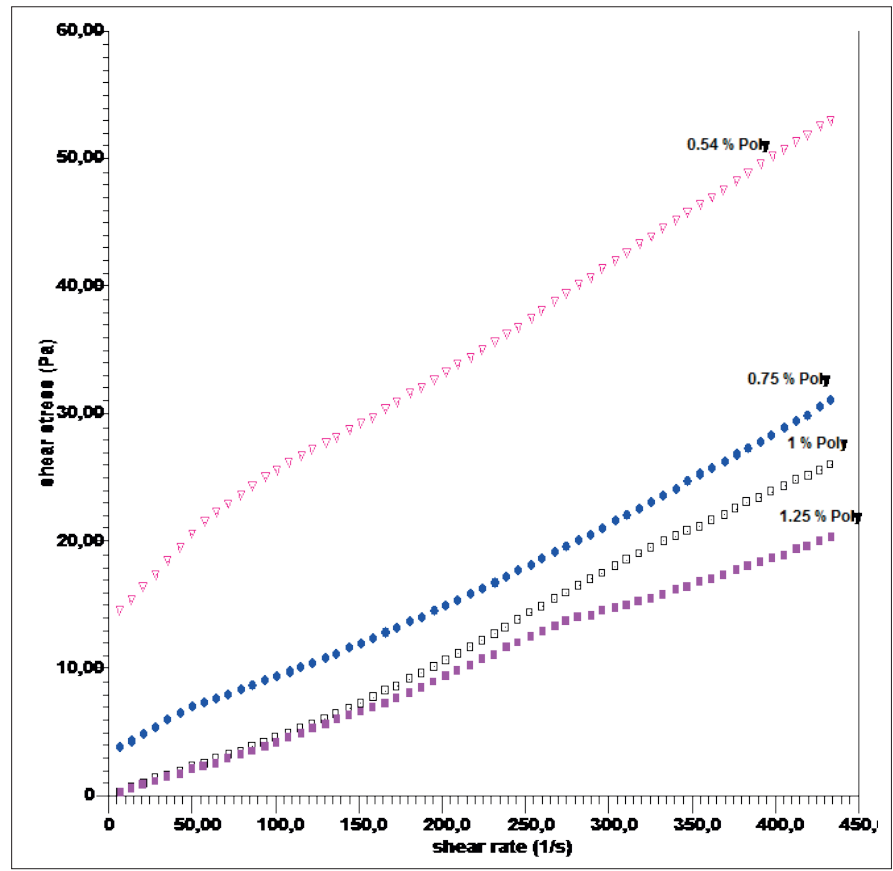

Fig. 6 Evolution of the rheological behavior of cementitious paste at different dosages of polycarboxylate

From Fig. 6, it can also be seen that the polycarboxylate plays the same role as the PNS and PMS (the shear stress decreases with the increase of the polycarboxylate dosage but with remarkable efficiency. Moreover, with a concentration of $0.54 \%$, the value of shear stress is only $14 \mathrm{~Pa}$ and it becomes very low at only $1 \%$. Moreover, with a concentration of $1.25 \%$, the flow of the paste (suspension of cement) approaches Newtonian behavior but can never be Newtonian.

Non-Newtonian fluids do not show a linear relationship between shear stress and shear rate. This is due to the complex structure and deformation effects exhibited by the materials involved in such fluids.

From Fig. 7, it can be noted that the yield stress decreases significantly with the increase of the polycarboxylate dosage. At $0.75 \%$, the yield stress recorded is estimated at 4.49 $\mathrm{Pa}$, a much lower value compared to those of the two previous superplasticizers (PNS $=21.05 \mathrm{~Pa}, \mathrm{PMS}=46.01 \mathrm{~Pa}$ ), this proves that this adjuvant is more dispersant.

On the other hand, three phases of behavior of the viscosity are distinguished as a function of the polycarboxylate dosage:
- Significant decrease between $0.54 \%$ and $0.75 \%$

- Relative stabilization between $0.75 \%$ to $1 \%$

- Light increase (low values: 0.019 to 0.0535 Pa.s) between 1 and $1.25 \%$, this is possibly due to the inverse effect of the superplasticizer.

This rheological performance is obtained by the length of the main chain as well as its grafting by side chains nonadsorbing which extend into the solution when the polymer is adsorbed. This is the action mode of polycarboxylate-based superplasticizers.

However, negative yield stress values may arise using $\mathrm{H}-\mathrm{B}$ model; this is due to experimental errors.

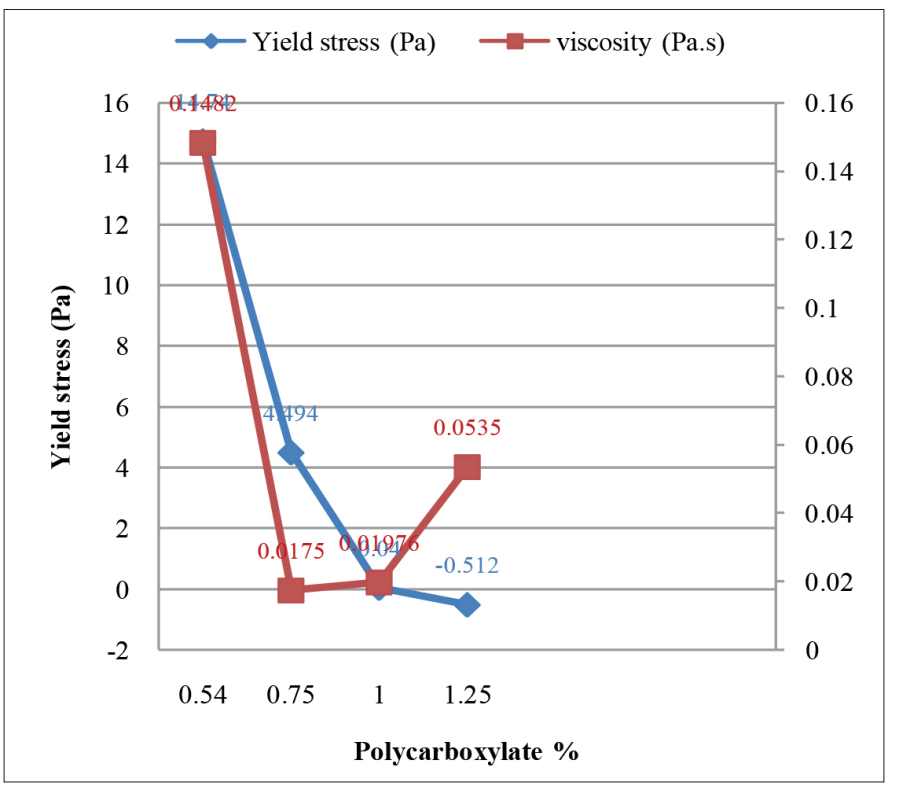

Fig. 7 Evolution of the rheological parameters as a function of Polycarboxylate \%

\subsection{Mechanism of action of Superplasticizers}

Overall, the fluidification of fresh concrete by the introduction of superplasticizers can be explained by the dispersion of the grains of cements. Superplasticizers are currently considered to be powerful dispersants. They make it possible to avoid the agglomeration of the cement particles and to release the water trapped in its agglomerates.

The deflocculation and the dispersion of the cement grains are directly linked to the adsorption of the superplasticizers on the surface of the cement particles. Consequently, the physical and chemical characteristics of the cement grains will be modified.

When a superplasticizer adsorbs on a cement grain, its dissociated acid functions modify the surface charges of the cement particles and minimize the interactions between this particles by creating repulsive forces.

\section{- Polycarboxylates}

The superplasticizers at the water/cement interface will also induce a short-range repulsive force due to the steric hindrance between two layers of polymers adsorbed on neighboring particles. 
The amplitude of the steric effects and the relative importance of the electrostatic and steric effects vary according to the type and the molar masses of the superplasticizers. For sulphonated superplasticizers (PNS and PMS), electrostatic effects are predominant [1].

For polycarboxylates, steric effects are predominant, in particular for polymers having long hydrophilic side chains. Because of their low charge density, the electrostatic effect of this class of superplasticizers is reduced compared with that of the sulfonated polymers.

\section{- Sulfonated polymelamines (PMS)}

belong to the category of superplasticizers/water reducers. They are effective at temperatures below $85{ }^{\circ} \mathrm{C}$ due to their limited chemical stability. They do not train air. They are preferred to PNS for resistance to fasting ages, by adsorbing on the hydrates being formed. The PMS superplasticizers interact with all the physico-chemical processes of hydration, so their role is not limited to a simple dispersing effect.

\section{- Sulfonated polynaphthalenes (PNS)}

have a dispersing efficiency linked to the nature of the cement. They are more retardant than PMS and are slightly air-cooled.

\subsection{Saturation point of superplasticizers}

Saturation point is the dosage beyond which the superplasticizer no longer has any effect on the rheological properties of the cement paste or concrete. In our pratical case, it was determined by the AR 2000 Rheometer.

Through the rheograms - flow curves illustrating shear stress vs shear rate for cement pastes -, and according to the rheological behavior obtained, yield stress and viscosity have been extracted. The evolution of these two rheological parameters as a function of the percentage of superplasticizer introduced is plotted and exploited.

From the results obtained from the rheological study (Fig. $2,3,4,5,6$ and 7), it is possible to estimate approximately the saturation point interval (percentage relative to the cement mass) of each superplasticizer which are as follows:

- Polycarboxylate $\approx 0,75$ to $1 \%$;

- Polynaphtalene sulfonate PNS $\approx 1,25$ to $1,75 \%$;

- Polymelamine sulfonate PMS $\approx 2$ to $2,5 \%$

\subsection{Self compacting concrete}

According to the saturation dosages intervals found in the rheological study, a pourcentage (\%) of each superplasticizer is used to prepare self-compacting concretes SCCs. The same cement and pozzolana are used as binder with a ratio $\mathrm{W} / \mathrm{C}+\mathrm{f}$ equal to 0,35 . The maximum aggregate size was chosen as 16 $\mathrm{mm}$. A fresh state characterization of these concretes was carried out according to the standardized tests of SCCs.

The results obtained are too mediocre: the concretes were very segregables and not homogeneous (sieve stability greater than 50\%).
To remedy this, other SCCs were made by keeping the same dosages of superplasticizers), but the ratio $\mathrm{W} / \mathrm{C}+\mathrm{f}$ was optimized.

The results obtained on fresh and hardened concrete are given in Table 3:

Where:

SCC-PNS: Self compacting concrete based polynaphtalene sulfonate.

SCC-PMS: Self compacting concrete based polymelamine sulfonate.

SCC-Poly: Self compacting concrete based polycarboxylate.

Table 3 Rheological and mechanical characteristics of SCCs.

\begin{tabular}{lccc}
\hline & SCC-PNS & SCC-PMS & SCC-Poly \\
\hline Superplasticizer $(\%)$ & 1.75 & 2.5 & 1 \\
W/C + F & 0.31 & 0.31 & 0.31 \\
Sieve stability $(\%)$ & 1 & 1 & 1,5 \\
Slump flow cone $(\mathrm{cm})$ & 72 & 72 & 73 \\
L-box $\left(\mathrm{H}_{1} / \mathrm{H}_{2}\right)(\%)$ & $>90$ & 90 & 90 \\
Compressive strength at & 39 & 47 & 41 \\
28 days $(\mathrm{MPa})$ & & & \\
\hline
\end{tabular}

From the results of Table 3, it can be said that very satisfactory rheological characteristics meeting the requirements of self-compacting concrete were reached with a water/cement + fine ratio of $0.31 \%$.

The maximum compressive strength is recorded by the PMS-based concrete, with a maximum value of $47 \mathrm{MPa}$, this is due to its effect of accelerator of hardening which will repercute positively on the mechanical resistances to the young ages.

It can also be concluded that the resistance to segregation is very satisfactory for all SCCs (verified by sieve stability), which can be explained by the decrease in the quantity of water and the increase of the superplasticizer dosages.

The test of slump flow bye Abrams cone is illustrated in Fig. 8

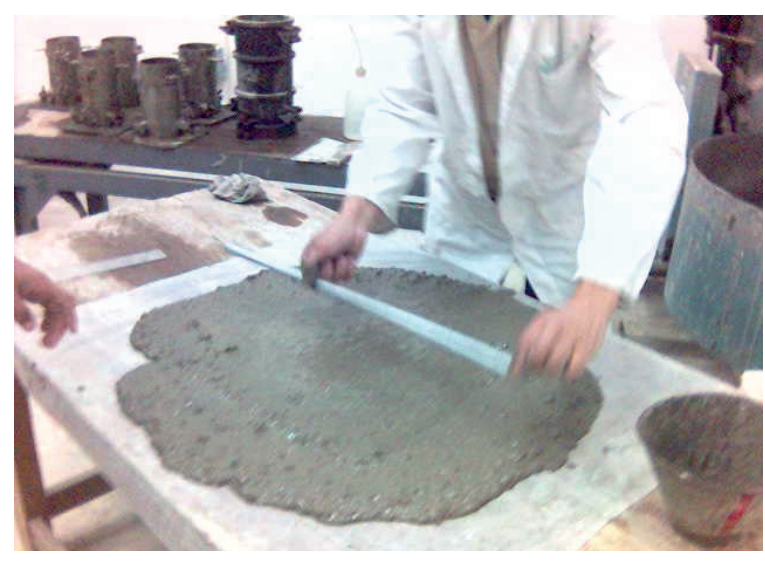

Fig. 8 Slump flow test by Abrams cone 


\section{Conclusions}

This experimental study allowed to understand the action of three types of superplasticizers (PNS, PMS and polycarboxylates) on the rheological and mechanical properties as well as the existing relation between the rheology of the cement pastes and their use in self-compacting concretes.

The superplasticizers have a critical concentration beyond which the adjuvant has no additional effect on the rheological properties of the concrete. This is called the saturation point.

The results of the tests performed on pastes with a coaxial cylinder rheometer indicated that the definition of the superplasticizer saturation point was more adequate when viscosity, and yield stress, was use as parameters affected by the admixture dosage.

The saturation dosages (intervals) of superplasticizers determined by rheometry on paste can be used for making self-compacting concretes, but the $\mathrm{W} / \mathrm{C}+\mathrm{F}$ ratio must be optimized (decrease). This will result in a gain in mechanical strengths.

The use of superplasticizer based PMS makes it possible to obtain better mechanical strengths at young age but with relatively high concentrations. On the other hand, the use of polycarboxylates favors obtaining excellent rheological properties with lower dosages with the same W/C + F.

Through the results of this study, it is advisable to start with the determination of saturation point of superplasticizer then to proceed with the formulation of the self-compacting concrete. This is valid if the obtaining of better rheological and mechanical properties is favored to the detriment of the economic aspect (use less quantity of superplasticizer because of its high price which will reflect negatively on the mechanical resistances since in this case the $\mathrm{W} / \mathrm{C}$ ratio should be increased.

The determination of a yield stress as a true material constant can be difficult as the measured value can be very much dependent on the measurement technique employed and the conditions of the test. In fact, negative yield stress values may arise. In order to avoid this, it is recommended:

First, do not let the sample lose the memory after the loading. It is very common to see at low shear stresses, negative shear rates. The reason is that the sample is moving the cylinder because of the residual stresses in one direction while the rheometer moves the cylinder in the other direction with a shear stress lower than the residual stress.

Second, to perform the experiment in a ramp instead of in a steady state experiment, it is almost mandatory to measure accurate yield stress the sample must be in equilibrium at each point of shear stress. If not we will have a yield stress that depends on the shear stress rate versus time.

Although the simplicity of H-B model could be naive to address more complex phenomena, it can be helpful in a fast screening and it is widely reported when studying this cement suspensions.

\section{Acknowledgement}

The study was performed with the financial support of the French-Algerian research collaboration (CMEP-Tassili) between the unit research: Materials, processes and environment (UR-MPE) of the Boumerdes University, Algeria, and the civil and mechanical engineering laboratory of INSARennes in France.

\section{References}

[1] Burgos-Montes, O., Palacios, M., Rivilla, P., Puertas, F. "Compatibility between superplasticizer admixtures and cements with mineral additions". Construction and Building Materials, 31, pp 300-309. 2012. https://doi.org/10.1016/j.conbuildmat.2011.12.092

[2] Plank, J., Winter, Ch. "Competitive adsorption between superplasticizer and retarder molecules on mineral binder surface". Cement and Concrete Research, 38(5), pp 599-605. 2008. https://doi.org/10.1016/j. cemconres.2007.12.003

[3] Rixom, R., Mailvaganam, N. "Chemical admixture for concrete". E \& FN Spon, London, 1999.

[4] EFNARC. "Specifications and guidelines for Self-compacting concrete". 2002. http://www.efnarc.org/pdf/SandGforSCC.PDF

[5] Okamura, H., Ouchi, M. "Self-compacting concrete". Journal of Advanced Concrete Technology, 1(1), pp. 5-15. 2003. https://doi. org/10.3151/jact.1.5

[6] Nunes, S. C. B. "Betão Auto-Compactável - Tecnologia e Propriedades", University of Porto, 2001. "Self- Compacting Concrete - Technology and Properties". in English. https://repositorio-aberto.up.pt/ bitstream/10216/11114/2/Texto\%20integral.pdf

[7] Cussigh, F. "Bétons auto-plaçants (BAP)". Technique de l'ingénieur, C 2 217. 2007.

[8] Benmounah, A,. Kheribet, R,. Samar, M,. Saidi, M,. "Comportement rhéologique des pâtes cimentaires destinées aux bétons autoplaçants", Revue Nature et Technologie, 1, pp. 74-88.2009. http://www.univ-chlef. dz/RevueNatec/art_01_08.pdf

[9] Melo, K. A., Repette, W. L. "Optimization of superplasticizer content in self-compacting concrete". In: Measuring, Monitoring and Modeling Concrete Properties, (Konsta-Gdoutos, M. S. (Ed.)). pp. 469-477. Springer, 2006. https://doi.org/10.1007/978-1-4020-5104-3_57

[10] Oualit, M., Si Ahmed, H. "Formulation et caractérisation rhéologique d'un béton autoplaçant (BAP): Action de differents superplastiants sur les propriétés rhéologiques". Mémoire de fin d'études, University of Boumerdès. Algéria.

[11] Spinosa, L., Lotito, V. "A simple method for evaluating yield stress". Advances in Environmental Research, 7(3), pp. 655-659. 2003. https://doi. org/10.1016/S1093-0191(02)00041-2

[12] Seyssiecq, I., Ferasse, J. H., Roche, N. "State-of-the-art: rheological characterization of waste water treatment sludge". Biochemical Engineering Journal, 16(1), pp. 41-56. 2003. https://doi.org/10.1016/S1369703X(03)00021-4

[13] Pevere, A.; Guibad, G., van Hullenbusch, E., Lens, P., Baudu, M. "Viscosity evolution of anaerobic granular sludgee". Biochemical Engineering Journal, 27(3), pp. 315-322. 2006. https://doi.org/10.1016/j. bej.2005.08.008 